REVIEW

\title{
Hypervirulent strains of Clostridium difficile
}

\author{
Barry Cookson
}

Postgrad Med J 2007;83:291-295. doi: 10.1136/pgmi.2006.056143

North America has seen increasing numbers of hospitalised patients and others in nursing homes and the community, with more severe Clostridium difficile associated diarrhoea. This is also described in Northern Europe and surveillance systems are being developed or improved to monitor the situation. One strain (ribotype O27) is described in detail and, like other emerging strains, is demonstrating increasing antimicrobial resistance, notably to quinolone antibiotics. However, its association with increased virulence is not straightforward, probably reflecting the interactions with differing patient case mix. There are many subtypes of the strain and more sophisticated typing and virulence assessment systems need to be developed using isolates carefully collected to test different epidemiological hypotheses. There are also environmental factors relating to treatment such as antimicrobials, cytotoxics and proton pump inhibitors. An emerging theme is the importance of aspects of healthcare delivery in contributing to the problem; this includes poorly maintained and cleaned healthcare premises, overcrowded hospitals and increased staffing workloads leading to poor compliance with infection control.

Correspondence to: Dr Barry Cookson, Centre for Infections, Health Protection Agency, 61 Colindale Avenue, London, NW9 5HT, UK; barry. cookson@hpa.org.uk

Received 4 December 2006 Accepted 16 January 2007
$\mathrm{T}$ he anaerobic, gram-positive, spore-forming bacterium Clostridium difficile was first isolated in $1935 .^{1}$ The designated name related to how difficult the original investigators found it to culture. It has been isolated widely in the soil and the gut of many animals and, although a known cause of colitis in animals such as cats, dogs, birds, rodents and neonatal pigs, it was not until $1978^{2}$ that it was found to also cause human disease (pseudomembranous colitis). Asymptomatic colonisation can occur and diarrhoea (Clostridium difficile associated diarrhoea $(C D A D))$ which varies in severity from mild to extremely severe. Pseudomembranous colitis is the most severe manifestation of disease, and is usually a pancolitis affecting especially the distal colon and rectum. However, a right-sided colitis is also described, featuring fever, pain, and decreased gut motility often with only mild diarrhoea. Toxic megacolon, with a mortality of $6-30 \%$, can also occur; narcotic use may increase its likelihood, and immunocompromised status and delayed diagnosis appear to result in higher mortality. Early intervention and aggressive management are key factors to recovery. However, significant mortality can also occur in the aged, even without colitis. ${ }^{3-5}$

\section{CAUSES OF CDAD}

Risk factors for CDAD comprise those that affect the gut microbial flora, the most common being exposure to antibiotics. Almost all antibiotics have been associated with CDAD, although it is less often associated with some-for example, metronidazole, aminoglycosides, trimethoprim and the quinolones (but see below). Clindamycin historically had a particularly infamous relationship to CDAD; animal work showed that following its use there was a particularly long period of gut susceptibility to the disease when challenged with $C$ difficile spores. ${ }^{6}$ CDAD is a disease predominantly of the aged, but other factors include recent gastrointestinal surgery and immunosuppressive therapy, including cytotoxics. ${ }^{5}$ Other independent risk factors described more recently comprise proton pump inhibitors which increase the risk threefold. ${ }^{7}$ It is presumed that increased gastric $\mathrm{pH}$ leads to decreased destruction of spores, but colonic receptors do exist for some proton pump inhibitors. ${ }^{8}$ Although CDAD is seen mainly inside hospitals and other healthcare settings, community $\mathrm{CDAD}$ is also described, although more epidemiological information is required..$^{10}$

\section{HYPERVIRULENT CDAD IN NORTH AMERICA}

Increased numbers of patients requiring colectomy alerted a hospital in Montreal, Quebec, Canada in 2002 to the possibility of CDAD with a higher severity, mortality and relapse rate. Over the next two years several investigations were performed: rates of CDAD were $\sim 28 / 1000$ admissions (five times the national average of 1997) with an extra 10.7 days in hospital and 30-day attributed mortality rates of $6.9 \%$, these being $0.8-2 \%$ in $1997 .{ }^{11-13}$ Perforations, toxic megacolon and colectomy rates had also increased. Between 2004 and 2005 it was estimated that over 14000 patients had been affected in the province of Quebec, with high mortality and relapse rates. By June 2006 the problem had spread to seven provinces with estimates of 13 cases per 1000 admissions. ${ }^{11-13}$ Risk factors compared with matched controls ${ }^{14}$ comprised, as in many previous studies, cephalosporins (odds ratio (OR) 3.8\%, 95\% confidence interval (CI) $2.2 \%$ to $6.6 \%$ ) and for the first time fluoroquinolones (OR 3.9\%, 95\% CI $2.3 \%$ to $6.6 \%) \cdot{ }^{15}$ Interestingly it may be that the association is only with certain quinolones; 8 methoxyquinolones (gatifloxacin and moxifloxacin) had been introduced recently in several of the affected centres, these agents having greater anaerobic

\footnotetext{
Abbreviations: CDAD, Clostridium difficile associated diarrhea; CDC, US Centres for Disease Control and Prevention; ECDC, European Centre for Disease Control; EU, European Union; MLST, multi-locus sequence typing; MRSA, methicillin-resistant Staphylococcus aureus; REA, restriction endonuclease
} 
activity. ${ }^{10}$ However, the situation with antibiotics was not straightforward, as patients received more antibiotics per case $(46 \%)$ than controls. ${ }^{14} 15$

Typing was performed (see later) and a new strain (ribotype O27) was isolated from $82 \%$ of patients. It was assumed that this was related to the increased virulence and relapse rate. There were other relevant factors, however; hospitals agreed that their case mix had changed over the last few years with greater numbers of debilitated, immunocompromised and elderly patients. ${ }^{11}$ Another interesting point is that the study of Pepin and colleagues ${ }^{14}$ did not show that proton pump inhibitors were an independent risk factor for CDAD, unlike the study quoted above. ${ }^{10}$ There are several possible explanations for this-for example, the patients may have been sicker or have some other missed risk factor. ${ }^{10}$ Such a risk factor might include patients admitted from the community. ${ }^{14}$

A similar situation to that in Canada had emerged in the USA, with the Centres for Disease Control and Prevention (CDC) showing rates had doubled between 1996 and 2003 from of 31 to 61 cases per 100000 . Isolates from six recent outbreaks in the USA revealed emergence of the same epidemic O27 strain. Higher morbidity and mortality were described in at least 17 states. ${ }^{15}{ }^{16}$ A nursing home outbreak of CDAD could be related to the switching from levafloxacin to gatifloxacin. ${ }^{10}$ There was a description of increasing CDAD in patients with low risk of the condition: only two isolates were typed and these were not the $\mathrm{O} 27$ strain. A leading article ${ }^{15}$ pointed out a need for better surveillance, case definitions and laboratory ascertainment. It also mentioned other issues such as the need for post-discharge surveillance due to delayed onset of diarrhoea after cessation of treatment and how best to select cases in case-controlled studies of antimicrobial usage.

\section{EUROPEAN CDAD}

Data from Europe have been reviewed recently ${ }^{17}$ and the European Centre for Disease Control (ECDC) has led an initiative to produce guidance for CDAD prevention, control and a research agenda. ${ }^{18}$ England is the only country with a mandatory reporting system; other countries in Europe did not have a surveillance system, but typed isolates causing outbreaks. Three other countries have described more virulent CDAD, the outbreaks being more difficult to control. In Belgium surveillance was started in June 2006: by July 2006 there were 11 hospitals with outbreaks and another two with sporadic cases of the 027 ribotype strain. ${ }^{19}$ In the Netherlands in April 2006 there were five hospitals with sporadic O27 isolates and 11 others with outbreaks; $22 \%$ deaths had occurred in one outbreak with a $19 \%$ relapse rates. Initially the spread of the strain could be tracked to the transfer of patients between hospitals. Guidelines and surveillance were progressed. Between September 2005 and June 2006, 556 patient isolates of $C$ difficile were typed and $\mathrm{O} 27$ was found to comprise $28 \%$ of cases. ${ }^{20-22}$

In Northern France in August 2006 there had been nine hospital outbreaks with O27 (194 cases) and 6\% attributable deaths. ${ }^{23}$ This situation had been related possibly to the transfer of French patients staying in Belgian elderly care homes but transferring to French hospitals when care was needed. Surveillance has also been started in France. A recent study in 212 hospitals in eight different countries showed that only $58 \%$ undertook investigations for CDAD when asked to so do by the clinicians and only $55 \%$ were able to culture the organism. ${ }^{24}$ In another study, an algorithm for testing increased numbers of detected cases by $20 \%{ }^{17}$ A recent report from Austria described a patient on vacation from the UK admitted to a hospital with O27-related CDAD: no spread was documented, ${ }^{25}$ but it again illustrates the potential for international spread of community and nosocomial pathogens.
There are concerns that CDAD is arising in the community. ${ }^{1017}$ In the Netherlands, for example, 36\% of CDAD patients had been admitted to a hospital. However, a third of these had been hospitalised in the previous month and $46 \%$ of them had experienced CDAD as a recurrence. ${ }^{17}$ This is not a new phenomenon; in the 1990s serious outbreaks of CDAD were sustained by admissions of patients with CDAD from the community, often with the same type as the outbreak strain (Cookson, unpublished observations).

Data from the English voluntary CDAD reporting system ${ }^{26}$ showed increasing numbers of CDAD cases from 1172 in 1990 to 46501 in 2004, with more dramatic increases since 2001 in the over 65 age group. Interestingly, highly significant increases in all age groups were observed, perhaps indicating a change in the dynamics of pathogenesis. The mandatory system reporting all cases over 65 years of age commenced in $2004,{ }^{26}$ when there were 44107 cases (555 per relevant 100000 population) increasing by $17.2 \%$ to 51690 (638) cases in 2005 . The report included an anecdotal statement that there was no clear relationship between severity of disease and O27, and that toxin production could vary. Notably the highest CDAD rates were seen in small acute hospitals, and there were possible decreases in cases over the quarters during 2005.

Rising numbers may be due to increasing case ascertainment. ${ }^{26}$ However, there are a number of reasons why this is unlikely: numbers of cases are also increasing in other countries; there are also increasing voluntary reports from the laboratory for all age groups; CDAD appears more often on hospital discharge diagnoses, as do the number of colectomies performed. There were also anecdotal views of infection control professionals stating that CDAD had increased. The report also provides data indicating rising numbers could not be related to an increasing aged population.

There was at the same time a report from the Office of National Statistics ${ }^{27}$ showing year on year increases between 2001 and 2004 in reports where CDAD was either mentioned, or stated to be the underlying cause, of patient mortality. Cases in 2004 (2247) were 130\% higher for either of these categories of reports than in 1999 (975 cases). Interestingly, in Wales the rise was less, there being an approximately 50\% increase in such reporting. CDAD comprised $0.52 \%$ and $0.46 \%$ of deaths occurring in hospitals and nursing homes, respectively, in England; interestingly, nursing home reports of CDAD deaths were very low in Wales. ${ }^{27}$ Mortality rates per million of the population by age and sex were listed, being very low below 54 years of age (2.6 per million) and much higher over 65 years $(28$ per million for males; 39 per million for females). This rise continued with increasing age: over 75 (around 153 per million for both sexes) and $>85$ years where the rates, interestingly, reversed ( 807 per million for males and 647 per million for females). These data indicate that the mortality related to CDAD was already increasing before the rise of the O27 strain.

The third influential report in 2006 came from the Healthcare Commission $^{28}$ following three outbreaks in 2003-05 at Stoke Mandeville Hospital affecting 498 patients. The investigation found that 127 of 172 hospital deaths were related to CDAD and in $4 \mathrm{l}$ of these it was the definite or probable cause. The report described many prevention and control issues relating to healthcare delivery (see below).

\section{MICROBIOLOGICAL ASPECTS OF C DIFFICILE}

Two recent papers have described the genetic background of $C$ difficile using differing methodologies and with different results. Multi-locus sequence typing (MLST of a diverse collection) by Lemee et $a^{29}$ found 34 sequence types, with no animal, geographical or virulent clones, although the well-described toxin A negative toxin B positive clone was distinct. Mutations 
were eightfold higher than recombination events and were seen to be the main driver for evolution. A ribotype $\mathrm{O} 27$ strain was included in the analyses, but was not found to be a unique sequence type.

Stabler $e t$ al $^{30}$ developed a microarray based on a sequenced multi-drug resistant ("630") strain from a patient with severe CDAD which had spread to dozens of other patients on the same ward in Zurich, Switzerland in 1982. They investigated 75 diverse isolates comprising hypervirulent, toxin-variable, and animal strains, and found four distinct, statistically supported clusters. One was a hypervirulent cluster and another the toxin A negative toxin B positive clone. Unfortunately, ribotypes are not listed in the paper, but an isolate of the Stoke Mandeville and Quebec outbreaks were included and related quite closely to each other. Moreover, using this methodology, only $19.7 \%$ of the wider spectrum of genes analysed were shared by all strains, and they concluded, unlike Lemee et al, ${ }^{29}$ that the organisms can indeed readily undergo genetic exchange. Interestingly, $11 \%$ of the DNA was related to mobile elements, including antimicrobial resistance. Several genetic islands were found relating to virulence, adhesion, antibiotic resistance, motility and enteric metabolism. There were no known sporeforming genes (ie, its sporulation mechanisms are quite different from known sequences). Interestingly the $\mathrm{ABC}$ transporter systems were located on conjugative transposons and may be relevant to the trigger factors of proton pump inhibitors and quinolones. The authors proposed that the substantial number of deletions seen in the hypervirulent isolates had created "black holes", perhaps related to "pathoadaptation" as seen in Shigella species. However, it is also possible that they were due to sequence diversity and it will be interesting to see how these isolates react to an array derived from the recently sequenced prototypic O27 C difficile strain.

Epidemic $C$ difficile isolates from North America, UK, Belgian, France and the Netherlands have been examined thus far. ${ }^{18}$ They are of ribotype $\mathrm{O} 27$ (this is a ribosomal 16S-23S spacer typing system with more than 150 types). It was first seen in 1988 when it was unimportant and rare. In the UK, for example, over $50 \%$ of CDAD isolates typed by the reference laboratory between 1995 and 2003 were of ribotype Ol and O27 was extremely rare. However, in randomised isolates referred to the laboratory in 2005, Ol, 106 and 27 each comprised about $25 \%$ of all isolates. ${ }^{26}$ A recent study in the Netherlands found that 027 strains of CDAD came from patients with less exposure to $\beta$-lactam antibiotics, and a trend to increased exposure to quinolones; interestingly they also had a longer interval between admission and development of CDAD. ${ }^{31}$

In the USA resistance is seen to moxifloxacin and gatifloxacin (historical isolates were sensitive) and in the UK isolates vary in quinolone and macrolide resistance; this is also true for other current strains of $C$ difficile ( $\mathrm{J}$ Brazier, personal communication, 2006). There may well be a need for isolates to be cultured and tested against a panel of antibiotics validated by reference laboratories within each country if such testing can usefully inform the local epidemiology and help the selection of isolates for further typing. There are 24 restriction endonuclease (REA) subtypes of $027,{ }^{18}$ but their utility for epidemiological studies has yet to be evaluated robustly. There is an urgent need to develop more sophisticated typing and virulence assessment systems using isolates collected carefully to test different epidemiological hypotheses.

\section{PATHOGENESIS OF CDAD}

When considering the pathogenesis of CDAD it is important to consider the interactions of the organism (the seed), the affected patients (soil) and the environment (climate). We have already mentioned various aspects of the patient case mix for the Canadian outbreaks and similarly alluded to the some of the climatic factors-for example, antibiotic and other drug usage. Although CDAD is under long and continuing study, much is still not known.

The inoculum, for example, may be very low. ${ }^{6}$ Several pathogenicity factors are described: there are two large exotoxins (TcdA\&B). However, TcdA-/B+ strains are recognised with increasing frequency and truncated $\mathrm{A} / \mathrm{B}$ strains can cause disease. ${ }^{318}{ }^{30}$ In $10 \%$ of selected strains there is a cdtA-B binary toxin encoding an actin-specific ADP-ribosyltransferase; this may just produce secretion of fluid by colonic cells but does not result in cell death. ${ }^{18}$ Many other factors may also be implicated, including fimbriae and subgroups of adhesions. ${ }^{3} 18$ O27 and Ol may produce higher sporulation levels than other strains and these were even higher when non-chlorinated disinfectants were used. ${ }^{18}$

Isolates of $\mathrm{O} 27$ from North America, UK, Belgium, France and the Netherlands thus far are of toxinotype III (this comprises testing TcdA,B and C a downward regulatory gene, there being 24 types). It usually contains an 18bp deletion in the TcdC gene. The cdtB toxin can vary even within European outbreaks. ${ }^{17}$ Warny et al ${ }^{32}$ found that Canadian strains had a one base pair deletion at codon 117 in TcdC. This resulted in more toxin production when they compared it to a toxinotype $\mathrm{O}$ strain. It should be noted that there has, however, been no consistent relationship between severity of disease and toxin concentration in stool. It is clear that, despite years of research, the organism has many hidden secrets and poses many interesting questions. A possible research agenda is outlined elsewhere $^{18}$ and lists several new proteomic and genetic techniques that should help answer them.

Interestingly, several of the infection control teams in Quebec comment that they no longer see as many cases of serious CDAD and think this may be related to their aggressive early treatment of infection as soon as the diarrhoea commences (personal communications to the author).

\section{PREVENTION AND CONTROL OF CDAD}

It is clear that the number of CDAD cases is increasing in many countries throughout the world. This may be related to new factors including the emergence of certain strains, their increasing antimicrobial resistance, the changing case mix, and aspects of healthcare delivery (see below). Prevention and control measures are being reviewed in many countries. The European Union (EU) is currently considering guidelines. Previous guidance was published in the UK in $1994^{5}$ and forms the basis for EU guidelines (P Gastermeier, personal communication, 2006). The evidence for their updating will need to be reviewed systematically and robust intervention studies designed if necessary. ${ }^{33}$ Control will be informed by improved surveillance and typing information. The guidelines point to reenforcement of all of the following: the use of hand washing for soiled hands or close contact with CDAD cases, isolation of patients with diarrhoea, effective stewardship of antibiotics, and decontamination of the environment. ${ }^{5}$

A new factor in the rubric of prevention and control are various aspects of clinical governance. These are apparent in reports from the Quebec and Stoke Mandeville outbreaks. ${ }^{11}{ }^{27}$ Staffing shortages, high bed occupancy, poorly cleaned and maintained premises, old buildings that need to be replaced, and low priority of infection control resonate in both countries. ${ }^{11} 27$ There are other interesting aspects about healthcare delivery. Patient transfers have resulted in the spread of the 027 strain between Belgian and France, and between hospitals in the Netherlands. ${ }^{17}{ }^{19}$ The $\mathrm{O} 27$ strain is now found in many parts of the UK ( $\mathrm{J}$ Brazier, personal communication, 2006), and it is interesting to speculate whether this may be 
caused by increased inter-city patient transfers due to patient choice? We described inter-city spread of epidemic methicillinresistant Staphylococcus aureus (MRSA) in the 1990s, perhaps encouraged by this process. ${ }^{34}$ Clearly a holistic approach to prevention and control will be required if we are to make any impact on the increasing numbers of CDAD cases described in many parts of the world.

\section{MULTIPLE CHOICE QUESTIONS (TRUE (T)/FALSE (F); ANSWERS AFTER THE REFERENCES} 1. Which of the following antibiotics are thought to be significant risk factors for CDAD caused by the 027 strain (there can be more than one)?
(A) Gentamicin
(B) Cephalosporins
(C) Trimethoprim
(D) Metronidazole
(E) Fluoroquinolones

\section{Which of the following are thought to be related to the increasing occurrence of CDAD in Canada (there can be more than one)?}

(A) Low priority for infection control

(B) Modern hospitals with too many side rooms

(C) Changing case mix-for example, more aged patients

(D) Changes in antibiotic prescribing

(E) Mainly due to increasing proton pump inhibitor usage

\section{Which of the following statements are true (there can be more than one)?}

(A) There is a consistent increase in mortality with the current $C$ difficile $\mathrm{O} 27$ strain

(B) $C$ difficile $\mathrm{O} 27$ comprises the majority of infecting strains in the UK

(C) $\mathrm{C}$ difficile $\mathrm{O} 27$ in Canada has been shown to have increased toxin production and levels of toxin in the stool are related to severity of disease

(D) Virulence in CDAD can probably be explained by a complex interaction between the organism, the affected patients and many aspects of healthcare delivery

(E) Surveillance and typing of $C$ difficile strains are important strategies in the control of CDAD

\section{Which of the following statements are true (there can be more than one)?}

(A) CDAD invariably causes severe diarrhoea

(B) CDAD can be readily identified by its self-limiting nature

(C) Toxic megacolon has a mortality of about $40 \%$

(D) Immunocompromised status and delayed diagnosis result in higher mortality in cases of toxic megacolon

(E) Significant mortality from CDAD can occur in the aged, even without colitis

Competing interests: None declared

\section{REFERENCES}

1 Hall IC, O'Toole E. Intestinal flora in new-born infants: with a description of a new pathogenic anaerobe, Bacillus difficilis. Am J Dis Child 1935;49:390-402.

2 Bartlett JG, Chang TW, Gurwith M, et al. Antibiotic-associated pseudomembranous colitis due to toxin-producing clostridia. N Engl J Med 1978:298:531-7.
3 Borriello SP. 12th C.L. Oakley lecture. Pathogenesis of Clostridium difficile infection of the gut. J Med Microbiol 1990;33:207-15

4 Spencer RC. Clinical impact and associated costs of Clostridium difficileassociated disease. J Antimicrob Chemother 1998;41(Suppl C):5-12.

5 Cooke EM, Borriello SP, Brazier JS, et al. DoH, PHLS Working Group. The prevention and management of Clostridium difficile infection. Heywood: BAPS Health Publications Unit, 1994

6 Larson HE, Borriello SP. Quantitative study of antibiotic induced susceptibility to Clostridium difficile enterocolitis in hamsters. Antimicrob Agents Chemother 1990;34:1348-53.

7 Dial S, Alrasadi K, Manoukian C, et al. Risk of Clostridium difficile diarrhea among hospital inpatients prescribed proton pump inhibitors: cohort and casecontrol studies. Can Med Assoc J 2004;171:33-8.

8 Nakamura M, Oda M, Akiba Y. Autoradiographic demonstration of lansoprazole uptake sites in rat antrum and colon. J Clin Gastroenterol 1995;20 et al. S8-13. (Suppl 2).

9 Simor AE, Bradley SF, Strausbaugh $\amalg$, et al. Clostridium difficile in longterm-care facilities for the elderly. Infect Control Hosp Epidemiol 2002;23:696-703

10 Gaynes R, Rimland D, Killum E, et al. Outbreak of Clostridium difficile infection in a long-term care facility: association with gatifloxacin use. Clin Infect Dis 2004;38:640-5.

11 Loo V, Libman MD, Miller MA, et al. Clostridium difficile: a formidable foe. Can Med Assoc J 2004;171:47-8.

12 Pepin J, Valiquette L, Cossette B. Mortality attributable to nosocomial Clostridium difficile-associated disease during an epidemic caused by a hypervirulent strain in Quebec. Can Med Assoc J. 2005 25;173: 1037-42, Also see:http:// www.eurosurveillance.org/ew/2005/050630.asp\#2 (Accessed 25 Nov 2006).

13 Poutanen SM, Simor AE. Clostridium difficile-associated diarrhea in adults. C Med Assoc J 2004:171:51-8.

14 Pepin J, Saheb N, Coulombe MA, et al. Emergence of fluoroquinolones as the predominant risk factor for Clostridium difficile-associated diarrhea: a cohort study during an epidemic in Quebec. Clin Infect Dis 2005;41: 1254-60.

15 McDonald C. Clostridium difficile: responding to a new threat from an old enemy. Infect Control Hosp Epidemiol 2005;26:672-5.

16 McDonald LC, Killgore GE, Thompson A, et al. An epidemic, toxin gene-variant strain of Clostridium difficile. N Engl J Med 2005;353:2433-41.

17 Kuijper EJ. Is Europe prepared for the new emerging Clostridium difficile PCR ribotype O27? ESCMID News. 2006;2: 8-10, http://www.escmid.org/Files/ News2_06_72dpi.pdf (accessed 25 Nov 2006).

18 Kuijper EJ, Coignard B, Tüll P, on behalf of the ESCMID Study Group for Clostridium difficile (ESGCD), EU Member States and the European Centre for Disease Prevention and Control. Emergence of Clostridium difficile-associated disease in North America and Europe. Clin Microbiol Infect 2006; 12(Suppl 6):2-18.

19 Joseph R, Demeyer D, Vanrenterghem D, et al. First isolation of Clostridium difficile PCR ribotype 027, toxinotype III in Belgium. Euro Surveill, 2005; 10.http://www.eurosurveillance.org/ew/2006/060504.asp (accessed 25 Nov 2006).

20 van Steenbergen J, Debast $S$, van Kregten $E$, et al. Isolation of Clostridium difficile ribotype 027, toxinotype III in the Netherlands after increase in $C$. difficile-associated diarrhoea. Euro Surveill. 2005;10: E050714, 1.http:// www.eurosurveillance.org/ew/2005/050714.asp\#1 (accessed 25 Nov 2006), (7).

21 Kuijper EJ, van den Berg RJ, Debast S, et al. Clostridium difficile Ribotype 027 Toxinotype III, the Netherlands. Emerg Infect Dis, 2006; 12(5).http:// www.cdc.gov/ncidod/eid/voll 2no05/05-1350.htm (accessed 25 Nov 2006).

22 van den Hof S, van der Kooi T, van den Berg R, et al. Clostridium difficile PCR ribotype 027 outbreaks in the Netherlands: recent surveillance data indicate that outbreaks are not easily controlled but interhospital transmission is limited. Euro Surveill. 2006;1 1: E060126, 2.http://www.eurosurveillance.org/ew/2006/ 060126.asp (accessed 25 Nov 2006), (1).

23 Tachon M, Cattoen C, Blanckaert K, et al. First cluster of C. difficile toxinotype III PCR-ribotype 027 associated disease in France:preliminary report. Euro Surveill. 2006; 1 1: 5, http://www.eurosurveillance.org/ew/2006/060504.asp (accessed 25 Nov 2006).

24 Barbut F, Delmee M, Brazier J, et al. A European Survey of diagnostic methods and testing protocols for Clostridium difficile. Clin Microbiol Infect 2003;9:989-96.

25 Indra A, Huhulescu S, Hasenberger P, et al. First isolation of Clostridium difficile PCR ribotype 027 in Austria. Eurosurveillance. 2006;11: 9, http:// www.eurosurveillance.org/ew/2006/060914.asp (accessed 25 Nov 2006)

26 Anon. Mandatory surveillance of healthcare associated infections report 2006a. Available on http://www.hpa.org.uk/infections/topics_az/hai/ MandSurvHCAl2006.pdf: (accessed 25 Nov 2006).

27 Anon. Report: deaths involving Clostridium difficile: England and Wales; $1999-$ 2004. Health Statistics Quarterly; Spring, 2006b: 56-60, http:// www.hpa.org.uk/infections/topics_az/clostridium_difficile/documents/ ReportDeathsinvolvingCdifficile.pdf(accessed 25 Nov 2006).

28 Anon. Investigation into outbreaks of Clostridium difficile at Stoke Mandeville Hospital, Buckinghamshire Hospitals NHS Trust. July 2006; ISBN: 1-84562-1034, http://www.healthcarecommission.org.uk/_db/_documents/ Stoke_Mandeville.pdf (accessed 25 Nov 2006).

29 Lemee L, Dhalluin M, Pestel-Caron J, et al. Multilocus sequence typing of human and animal Clostridium difficile isolates of various toxigenic types. J Clin Microbiol 2004:42:2609-17. 
30 Stabler RA, Gerding DN, Songer SD, et al. Comparative phylogenomics of Clostridium difficile reveals clade specificity and microevolution of hypervirulent strains. J Bacteriol 2006;188:7297-305

31 Goorhuis A, Vaessen N, Harmanus C, et al. Interim results of the National Reference Laboratory for Clostridium difficile in the Netherlands. J Hosp Infect. 2006;64(Suppl 1): 4-5, FP2.04.

32 Warny M, Pepin J, Fang A, et al. Toxin production by an emerging strain of Clostridium difficile associated with outbreaks of severe disease in North America and Europe. Lancet 2005;366:1079-84.

33 Stone S, Cooper B, Cookson B, et al. The ORION Statement: a CONSORT equivalent for infection control studies - guidelines for transparent reporting of outbreak reports and intervention studies of Nosocomial infection. J Hosp Infect. 2006;64(Suppl 1): 40, P7.02.Draft available on:http://www.bsac.org.uk/_db/ documents/FINAL ORION.doc.
34 Murchan S, Aucken HM, O'Neil G, et al. Emergence, spread and characterisation of phage variants of epidemic methicillin-resistant Staphylococcus aureus - 16 (EMRSA-16) in England and Wales. J Clin Microbiol 2004; $57: 345-6$

\section{ANSWERS}

1. (A) $\mathrm{F}(\mathrm{B}) \mathrm{T}(\mathrm{C}) \mathrm{F}$ (D) $\mathrm{F}(\mathrm{E}) \mathrm{T}$

2. (A) $\mathrm{T}(\mathrm{B}) \mathrm{F}(\mathrm{C}) \mathrm{T}(\mathrm{D}) \mathrm{T}(\mathrm{E}) \mathrm{F}$

3. (A) $\mathrm{F}(\mathrm{B}) \mathrm{F}(\mathrm{C}) \mathrm{F}(\mathrm{D}) \mathrm{T}(\mathrm{E}) \mathrm{T}$

4. (A) $\mathrm{F}(\mathrm{B}) \mathrm{F}(\mathrm{C}) \mathrm{F}(\mathrm{D}) \mathrm{T}(\mathrm{E}) \mathrm{T}$

\section{bmjupdates+}

bmjupdates+ is a unique and free alerting service, designed to keep you up to date with the medical literature that is truly important to your practice.

bmjupdates+ will alert you to important new research and will provide you with the best new evidence concerning important advances in health care, tailored to your medical interests and time demands.

Where does the information come from?

bmjupdates+ applies an expert critical appraisal filter to over 100 top medical journals A panel of over 2000 physicians find the few 'must read' studies for each area of clinical interest

Sign up to receive your tailored email alerts, searching access and more...

www.bmjupdates.com 